\title{
THE ROLE OF THE VESTIBULAR APPARATUS IN THE PRO- DUCTION OF NAUSEA AND VOMITING FOLLOWING THE ADMINISTRATION OF MORPHINE TO MAN
}

\author{
CLINICAL AND EXPERIMENTAL DATA INCLUDING THE EFFECTS OF DRAMAMINE AND \\ BENZEDRINE
}

\author{
By ALAN RUBIN and JULIUS WINSTON
}

\begin{abstract}
(From the Department of Pharmacology and Otolaryngology, Unizersity of Pennsyluania School of Medicine, and the Department of Obstetrics and Gynecology, Hospital of the University of Pennsylvania, Philadelphia)
\end{abstract}

(Submitted for publication March 1, 1950; accepted, June 20, 1950)

Morphine has among its disturbing side effects the production of nausea and emesis. While this action is said to be "central" in origin (1), or due to "stimulation of the vomiting center" (2), certain clinical and experimental observations have led us to attempt a further elucidation of the mechanisms involved. We have endeavored to gain this information with the hope that a rational approach might be provided toward preventing or diminishing this emetic activity.

Ambulation has been shown to increase the incidence of nausea and vomiting following the administration of morphine. At a state cancer hospital the incidence of nausea in bed patients given morphine was $3 \%$ (3). Of the entire group, $2.6 \%$ had emesis. In ambulatory subjects given $15 \mathrm{mg}$. of morphine subcutaneously, Comroe and Dripps (4) found that $40 \%$ were nauseated and $16 \%$ vomited. Wangeman and Hawk (5), during experiments with morphine, noted that motion or minor changes of position produced nausea which could be relieved by rest and recumbency.

These studies suggested that morphine may disturb vestibular function, and that the vestibular activity incident to ambulation may then result in an increase in nausea and emesis. To investigate this possibility, we have examined the responses to vestibular stimulation in healthy adults before and after the administration of morphine.

We have shown elsewhere (6) that the results of tests of vestibular function performed in the same normal individual one week apart vary slightly in a purely random fashion. If morphine should influence the vestibular apparatus to an extent demonstrable by our method, an alteration from this random variation might be anticipated.

\section{METHODS}

Twenty normal male medical students were studied (ages 21-37). No subject knew whether a drug or placebo was given, nor that morphine was being investigated. Two examinations, one week apart, were performed on each individual. To 14 subjects, 45 minutes to three hours before one examination, $15 \mathrm{mg}$. of morphine sulfate were given subcutaneously. Before the other examination, a saline placebo was injected. Each subject thus served as his own control. Subjects were observed one hour after a light lunch. Each subject was seated in a standard Barany chair, his head supported by a head rest, and flexed toward his chest so that the vertical axis of his head was $30^{\circ}$ forward and the external canthus of each eye was on a horizontal line with the ipsilateral tragus. With his eyes closed, the subject was then noiselessly turned at constant velocity, one turn per two seconds, for a total of 10 turns, in $20 \pm 0.25$ seconds. Following the rotation, the subject looked without visual fixation straight forward into the distance, and indicated the instant at which all sensation of rotation ceased. This was called the duration of post-rotational vertigo. The subject's nystagmus was observed concomitantly, and its precise duration as noted by the unaided eye of the investigator was recorded. (The same observer was employed throughout the study.) Three minutes after the cessation of nystagmus and vertigo, the procedure was repeated, this turning being in the opposite direction to the first one. Thirty minutes later, with the subject supine, mass caloric stimulation was applied by running water at $68^{\circ} \mathrm{F}$. $\left(20^{\circ} \mathrm{C}\right.$. $)$ into one ear. The time required for the production of a horizontal nystagmus was noted. The subject then sat up, and the presence of a rotary nystagmus from stimulation of the vertical semicircular canals ascertained. After a five minute rest, the same caloric test was performed on the opposite ear. The blood pressure (Riva-Rocci) and pulse rate were determined prior to each injection, before and after the turning test, and with the subject supine, before and after caloric stimulation. Gait and station (including the Romberg test), pointing, finger-tonose test, and spontaneous and voluntary ocular movements were noted before and after the placebo and morphine. An audiogram was made after each injection. A 


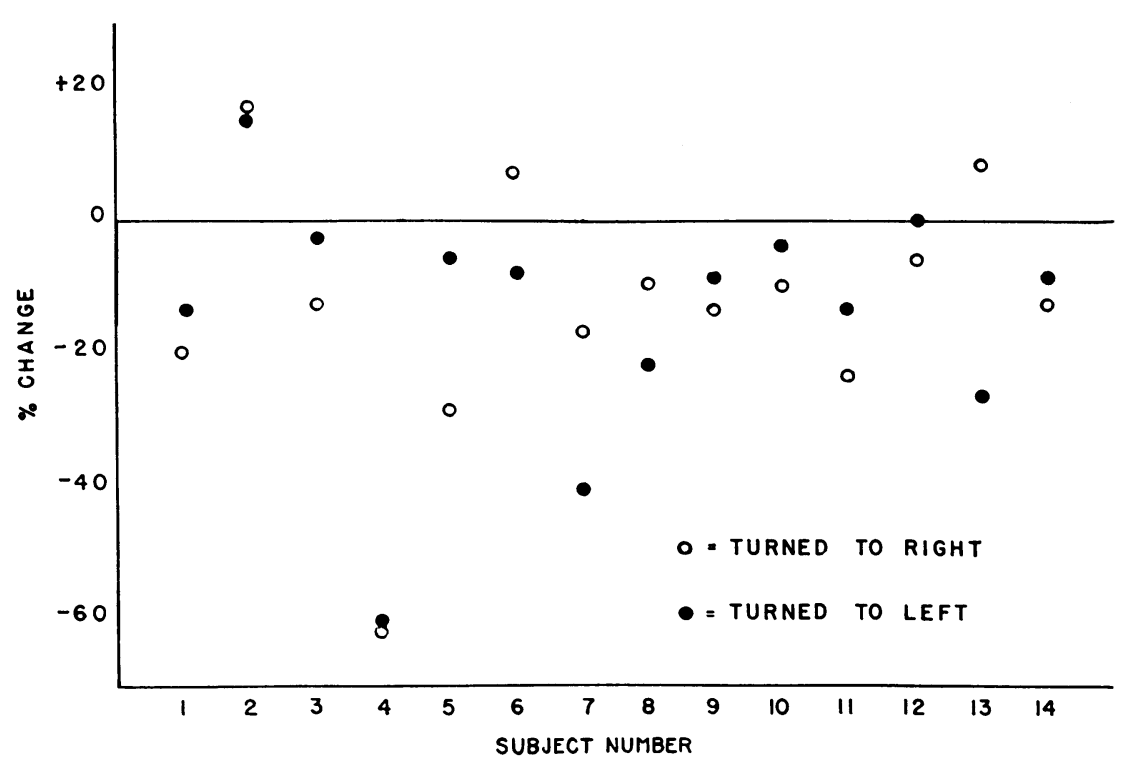

Fig. 1. Percentage Change from Control in Duration of Post-Rotational Nystagmus following Morphine

record of other signs and symptoms such as emesis, nausea, sweating, and pallor was kept throughout the experiment and for 10 hours thereafter. Six subjects were given a morphine-placebo and morphine-Dramamine combination as described later.

\section{RESULTS}

A. Turning test (Table I and Figure 1). After morphine, the duration of post-rotational nystagmus decreased in 23 determinations, was unchanged in one and increased in four as compared with the values following a placebo. The mean decrease was $12.3 \% .^{1}$ The probability of a decrease of this magnitude being due to chance alone is less than one in one hundred $(t=3.27)$. There was no significant difference in the decrease after turning to the right compared with the decrease after turning to the left.

The duration of vertigo after morphine decreased 19 times, was unchanged twice and increased seven times. The mean fall was $12.7 \%$. This decrease was also statistically significant.

There was no discernible difference in the degree of depression of nystagmus and vertigo between subjects tested 45 minutes after receiving morphine and those tested two to three hours after the administration of the drug.

1 Similar results have been obtained in a smaller group of individuals given Dilaudid or Demerol.
B. Caloric stimulation. Following the injection of morphine there was slight bilateral decrease in vestibular response to cold water. With the subject supine, the duration of the stimulus required for the appearance of a horizontal nystagmus was increased in 15 determinations, was unchanged in three, and diminished slightly in 10 . After the production of a horizontal nystagmus, all but two individuals displayed a normal rotary nystagmus upon sitting up. This indicated that the vertical semicircular canals were usually capable, as they should be in normal individuals, of producing a visible response to the stimulus which had just induced a response from the hori-

TABLE I

Mean duration (in seconds) of post-rotational nystagmus and vertigo for 14 subjects

Right and left indicate the direction of the turn.

\begin{tabular}{l|c|c|c|c}
\hline & \multicolumn{2}{|c|}{ Nystagmus } & \multicolumn{2}{c}{ Vertigo } \\
\cline { 2 - 5 } & Right & Left & Right & Left \\
\hline Placebo & 23.2 & 23.4 & 18.9 & 18.1 \\
\hline Morphine, 15 mg. s.c. & 20.3 & 20.6 & 16.2 & 16.1 \\
\hline Mean difference & -2.9 & -2.8 & -2.7 & -2.0 \\
\hline S. E. Mean diff. & .92 & .82 & 1.24 & 1.20 \\
\hline Mean difference $\%$ & -12.5 & -12.0 & -14.3 & -11.1 \\
\hline
\end{tabular}


TABLE II

Mean change in blood pressure ( $m m$. mercury) and pulse rate (beats per minute) following vestibular stimulation in the supine or sitting subject

\begin{tabular}{|c|c|c|c|c|}
\hline \multirow{2}{*}{ Drug } & \multicolumn{2}{|c|}{ Blood pressure } & \multicolumn{2}{|c|}{ Pulse rate } \\
\hline & Sitting & Supine & Sitting & Supine \\
\hline Placebo & $1.5 / 3.8$ & $0 / 0$ & -1.5 & -1.0 \\
\hline Morphine, 15 mg. s.c. & $2.8 / 0$ & $2.0 /-0.8$ & -4.4 & -1.4 \\
\hline $\begin{array}{l}\text { Benzedrine, } 20 \text { mg. i.m., } \\
\quad \frac{1}{2} \mathrm{hr} \text {. after morphine, } \\
15 \mathrm{mg} \text {. s.c. }\end{array}$ & $2.4 / 4.3$ & & -.3 & \\
\hline
\end{tabular}

zontal canals. In two subjects, however, the left vertical canals showed no response, although following the placebo, they were responsive to a stimulus of shorter duration.

C. Neurological examination; audiograms. After morphine, three subjects had a slightly ataxic gait. One of these individuals spontaneously past-pointed four inches medially with each hand. No other abnormalities were noted. All subjects had negative Romberg tests. Audiograms following morphine were essentially unchanged from the controls. The agreement was within \pm 10 decibels over a frequency of 128 to 8,192 cycles per minute. Mild euphoria was experienced by the majority of the subjects.

D. Blood pressure and pulse rate (Table II). Following the placebo, vestibular stimulation produced no significant changes in blood pressure or pulse rate. These results are in general agreement with those of Hemingway (7), whose subjects were studied after sitting in an oscillating swing. After vestibular stimulation, in our subjects given morphine there was a tendency for the pulse rate to fall slightly, especially with the subject in the sitting posture. The mean decrease was 4.4 beats per minute. The blood pressure was not appreciably altered.

E. Symptoms (Table III). After the placebo, only one subject experienced nausea and emesis. This followed caloric stimulation. After morphine, prior to the vestibular stimulation, three subjects noted nausea and one vomited. Two persons volunteered the information that rotation of the head from side to side increased their nausea and produced dizziness. During the testing of the subjects examined two to three hours after the injection of morphine, $87.5 \%$ became nauseated, and $62.5 \%$ vomited. Of those tested 45 minutes after injection, $16.6 \%$ vomited, and $50 \%$ were nauseated. The alterations in vestibular function were essentially the same for the two groups.

F. Effect of benzedrine (Tables II and III). Benzedrine has recently been combined with morphine in an attempt to reduce the incidence of post-morphine vomiting $(8,9)$. It has also been reported to be effective in the treatment of seasickness (10). Twenty mg. of benzedrine sulfate (N.N.R.) were given intramuscularly at the conclusion of the ear douching to 10 of the subjects who had just been tested with morphine. Thirty minutes later, each was turned in the Barany chair as before. The benzedrine had no apparent effect either in ameliorating nausea and vomiting once they had appeared, or in protecting against their appearance following vestibular stimulation. Fifteen minutes after the injection of the benzedrine, one of the subjects not previously ill suddenly vomited. Six of the other 10 either remained nauseated or became so when the turning test was performed 30 minutes after the administration of benzedrine. Four of these 10 subjects vomited immediately after this turning. There was no alteration in vestibular response to rotation. All subjects given benzedrine developed a tachycardia and slight hypertension (average pulse rate 84 , blood pressure $130 / 90$; prebenzedrine: average pulse rate 66 , blood pressure 108/68). Following turning, both systolic and diastolic blood pressures showed a slight tendency to increase (average rise $2.4 / 4.3 \mathrm{~mm}$. of mercury).

Symptoms of nausea and slight vertigo usually persisted for six to eight hours after the comple-

\section{TABLE III}

Nausea and emesis following vestibular stimulation (includes total for turning test and caloric stimulation)

\begin{tabular}{|c|c|c|c|}
\hline \multirow{2}{*}{ Drug } & \multirow{2}{*}{$\begin{array}{l}\text { No. of } \\
\text { subjects }\end{array}$} & \multicolumn{2}{|c|}{$\%$ Subjects with } \\
\hline & & Nausea & Emesis \\
\hline Placebo, s.c. & 14 & 7.1 & 7.1 \\
\hline $\begin{array}{l}\text { Morphine, } 15 \mathrm{mg} . \text { s.c. } \\
\text { Tested } \frac{3}{4} \text { hour af ter injection } \\
\text { Tested } 2-3 \text { hours after injection }\end{array}$ & $\begin{array}{l}6 \\
8\end{array}$ & $\begin{array}{l}50.0 \\
87.5\end{array}$ & $\begin{array}{l}16.6 \\
62.5\end{array}$ \\
\hline $\begin{array}{l}\text { Benzedrine, } 20 \mathrm{mg} . \text { i.m., } \frac{1}{2} \text { hour } \\
\text { after morphine, } 15 \mathrm{mg} . \text { s.c. }\end{array}$ & 10 & 70.0 & 40.0 \\
\hline
\end{tabular}


TABLE IV

Nausea and emesis following turning test in six subjects

\begin{tabular}{|c|c|c|}
\hline \multirow{2}{*}{ Drug } & \multicolumn{2}{|c|}{$\%$ Subjects with } \\
\hline & Nausea & Emesis \\
\hline Placebo alone & 0 & 0 \\
\hline Morphine, 15 mg. s.c., plus placebo p.o. & 83.3 & 66.7 \\
\hline $\begin{array}{l}\text { Dramamine, } 100 \mathrm{mg} . p . o . \text {, one hour before } \\
\text { and one hour after morphine, } 15 \mathrm{mg} . \text { s.c. }\end{array}$ & 0 & 0 \\
\hline
\end{tabular}

tion of the experiment, whether the subject received benzedrine or not. After the administration of benzedrine, four individuals noted an increase in their euphoria.

G. Effect of Dramamine" (Table IV). Dramamine has been reported as useful in the prevention of motion sickness (11). Since morphine apparently produced a vestibular disturbance, a trial of Dramamine after morphine seemed indicated to see if the evidences of vestibular dysfunction would be altered.

Six medical students not included in the studies so far mentioned served as subjects. Each received $100 \mathrm{mg}$. of Dramamine orally, followed one hour later by $15 \mathrm{mg}$. of morphine sulfate subcutaneously. One hour afterward, another $100 \mathrm{mg}$. of Dramamine was taken by mouth. An hour after this, that is, two hours after the morphine, the turning test was performed. A similar trial a week later was performed with morphine, but with a placebo substituted for the Dramamine. The difference in symptoms between the two trials was marked. With the morphine plus Dramamine, none of the subjects had any nausea or emesis following vestibular stimulation. With the morphine-placebo combination five had severe nausea and four vomited. Turning following only placebos resulted in no nausea or emesis in this group. There was no significant difference in vestibular test response between the morphineplacebo and morphine-Dramamine combinations. Neither the subjects nor the observers noted any increased sedation with the morphine-Dramamine combination.

$2 \boldsymbol{\beta}$-dimethylaminoethyl benzohydryl ether 8-chlorotheophyllinate. Supplied by Dr. I. C. Winter of G. D. Searle, Chicago, Ill.
Because of the encouraging results we have observed with Dramamine after morphine, ${ }^{3}$ we are at present administering Dramamine as part of the pre-anesthetic medication where opiates are employed in the hope that post-anesthetic nausea and vomiting will be diminished.

\section{DISCUSSION}

These studies show that the nauseant and emetic effects of morphine are markedly enhanced by vestibular stimulation.

We have been able to demonstrate in man by a simple testing technique a significant alteration in vestibular responses following the administration of morphine.

This vestibular disturbance might be due to or associated with several factors:

a. Cerebral circulatory changes. Drew, Dripps, and Comroe (12) reported a high incidence of syncope in subjects who were tilted to the head up position after receiving morphine. Since the assumption of the head up posture was followed by a fall in blood pressure, the authors suggested that peripheral vasodilation due to morphine resulted in a fall in blood pressure and consequent cerebral anemia. They later (4) proposed that cerebral circulatory changes incident to the erect posture might account for the increase in emesis seen with morphine in ambulatory subjects. While it is possible that cerebral anemia may have been a factor in the vestibular changes in our subjects, vestibular stimulation after morphine produced a high incidence of nausea and vomiting whether the subjects were supine or erect. There

\footnotetext{
3 We have noted marked clinical improvement in subjects given Dramamine for nausea and emesis occurring after the administration of morphine, Dilaudid, or Demerol. Several individuals who after these drugs complained of severe vertigo and nausea, often markedly accentuated by head movement, had a complete cessation of symptoms within 30 minutes after ingesting $100 \mathrm{mg}$. of Dramamine. These subjects had been unrelieved by such remedies as sodium phenobarbital hypodermically, sodium bicarbonate, or intravenous glucose or saline. One person, whose severe post-morphine vomiting included her ingested Dramamine tablet, was completely relieved shortly after the rectal administration of $100 \mathrm{mg}$. of Dramamine. So far we have seen no clinical evidence of excessive sedation or other untoward effects with the two drugs used in combination.
} 
were also no significant changes in blood pressure or pulse rate on testing after morphine.

b. Gastrointestinal changes. Abbott and Pendergrass (13) observed fluoroscopically that morphine produced duodenal spasm. Ingelfinger and Moss (14) induced similar spasm by douching the ear with cold water, and frequently noted nausea coincident with the spasm. Since morphine apparently affects the vestibular apparatus, perhaps some of the gastrointestinal changes seen after this drug may be related to, or enhanced by its vestibular action.

c. Direct effect on emetic center or vestibular apparatus. We cannot offer information on the possibility that morphine may affect the emetic center as well, and by increasing its sensitivity, make it more responsive to vestibular disturbances. However, the apparent dissociation of horizontal from vertical semicircular canal response seen in several of our subjects suggests that at least part of the vestibular effect of morphine is in the central nervous system, rather than in the vestibular end organ. If the action were peripheral, one would expect a parallel change in function of both the vertical and horizontal canals (15)."

This work suggests that the avoidance of vestibular stimulation in subjects given morphine will diminish the nauseant and emetic effects of the drug. Hence, ambulation, or such actions as the patient's frequent turning of the head to look from one visitor to another, should be curtailed after morphine has been administered. Dramamine may be given prophylactically.

\section{SUMMARY AND CONCLUSIONS}

1. A simple technique for assessing the effect of drugs on vestibular function in man has been described.

2. Morphine sulfate produced a significant decrease in vestibular response.

\footnotetext{
4 Further evidence for a central locus of action is suggested by the sudden appearance of a spontaneous vertical nystagmus downward on downward gaze which occurred in an ambulatory hospital patient two hours after being given $15 \mathrm{mg}$. of morphine subcutaneously. She had a $20 \%$ decrease in post-rotational nystagmus and vertigo as compared with results obtained several days later after a saline placebo. She was made severely ill, with six hours of violent emesis, vertigo and ataxia. In 24 hours she was symptom-free and her nystagmus had disappeared.
}

3. Vestibular stimulation following the administration of morphine sulfate resulted in a marked increase in nausea and emesis.

4. Vestibular stimulation following morphine resulted in no significant changes in blood pressure or pulse rate.

5. Benzedrine sulfate was of no apparent benefit in relieving the emesis accompanying vestibular stimulation in subjects under the influence of morphine.

6. Dramamine given either orally or rectally appeared to prevent and relieve post-morphine, Dilaudid and Demerol nausea, vomiting and vertigo, and its use therapeutically and prophylactically with these drugs was suggested.

7. Neither Dramamine nor benzedrine altered the vestibular changes produced by morphine.

We wish to acknowledge the aid and encouragement of Professors Carl F. Schmidt, Harry P. Schenck, and Robert D. Dripps.

\section{BIBLIOGRAPHY}

1. Sollman, T. H., A Manual of Pharmacology and its Applications to Therapeutics and Toxicology. W. B. Saunders Co., Philadelphia, 1948, 7th ed.

2. Goodman, L., and Gilman, A., The Pharmacological Basis of Therapeutics. Macmillan Co., New York, 1941.

3. Lee, L. E., Jr., Studies of morphine, codeine and their derivatives; clinical studies of morphine, methyldihydromorphine (metopon) and dihydrodesoxymorphine-D (desomorphine). J. Pharmacol. \& Exper. Therap., 1942, 75, 161.

4. Comroe, J. H., Jr., and Dripps, R. D., Reactions to morphine in ambulatory and bed patients. Surg., Gynec. \& Obst., 1948, 87, 221.

5. Wangeman, C. P., and Hawk, M. H., The effects of morphine, atropine, and scopolamine on human subjects. Anesthesiology, 1942, 3, 24.

6. Rubin, A., and Winston, J., The vestibular responses to turning, with nomograms for the detection of streptomycin and other drug toxicities. Ann. Otol., Rhin. \& Laryng., in press.

7. Hemingway, A., Cardiovascular changes in motion sickness. J. Aviation Med., 1945, 16, 417.

8. Guyot, J. DeV., Use of benzedrine to overcome untoward effects of morphine in the treatment of coronary occlusion. J. Missouri M. A., 1941, 38, 93.

9. Rubin, A., Metz-Rubin, H., and Dripps, R. D., Unpublished observations.

10. Albrecht, F. K., A therapeutic evaluation of benzedrine sulfate in the treatment of seasickness; results in 100 cases. M. Clin. North America, 1943, 27, 1652. 
11. Gay, L. N., and Carliner, P. E., The prevention and treatment of motion sickness. I. Seasickness. Bull. Johns Hopkins Hosp., 1949, 84, 470.

12. Drew, J. H., Dripps, R. D., and Comroe, J. H., Jr., Clinical studies of morphine. II. The effect of morphine upon the circulation of man and upon the circulatory and respiratory responses to tilting. Anesthesiology, 1946, 7, 44.
13. Abbott, W. O., and Pendergrass, E. P., Intubation studies of human small intestine. V. Motor effects of single clinical doses of morphine in normal subjects. Am. J. Roentgenol., 1936, 35, 289.

14. Ingelfinger, F. J., and Moss, R. E., Activity of the descending duodenum during nausea. Am. J. Physiol., 1942, 136, 561.

15. Jones, I. H., and Fisher, L., Equilibrium and Vertigo. Lippincott \& Co., Philadelphia, 1918.

\section{NOTIFICATION TO SUBSCRIBERS \\ FOR CHANGES IN RATES FOR 1951 NEW AND RENEWAL SUBSCRIPTIONS}

Effective October 1, 1950, new and renewal orders for Volume 30,1951 , will be $\$ 12.00$ (payable in U. S. funds), instead of $\$ 10.00$. Subscriptions are on a January through December or July through June basis.

Special rate for medical students, interns, residents and fellows will be $\$ 6.00$ instead of $\$ 5.00$ as formerly.

Vols. 1-11, inc. (1924-1932)-Special Sales Price, while available, \$25.00. Vol. 12 (1933) through Vol. 29 (1950), $\$ 10.00$ a volume.

All single copies from Vol. 1, No. 1 through Vol. 28, No. 6, $\$ 2.00$ each. Vol. 29 (1950), No. 1, on-\$1.50 each. 